\title{
STUDYING THE EFFECT OF CHEMICAL TREATMENT AND ORIENTATION ON FRACTURE TOUGHNESS OF KENAF FIBRE- EPOXY COMPOSITES
}

\author{
Mushtaq Albdiry, \\ Department of Materials Engineering, University of Al-Qadisiyah, Iraq. \\ E-mail:mushtaqalbdiry@gmail.com; mushtaq.taleb@qu.edu.iq
}

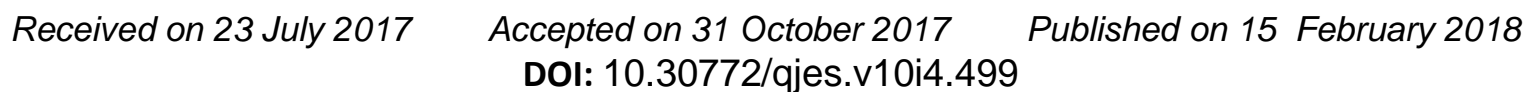

\begin{abstract}
In this paper, the effect of surface modification and fibre arrangements of kenaf fibers on fracture toughness of epoxy composite was investigated. The chemical treatment of kenaf fibers (KFs) with $6 \% \mathrm{NaOH}$ was achieved, and composites with two different fibre arrangements ( $X$ and $Y$ ) directions were fabricated. Values of fracture toughness (KIC) measured of the compact tension (CT) specimens for both untreated kenaf fibre-reinforced epoxy (ut-KFRE) composites and treated kenaf fibre-reinforced epoxy (treated-KFRE) were much better than the neat epoxy. The $K_{1 c}$ value of the treated-KFRE composite in $Y$-fibre direction was the highest of 2.74 MPa.m1/2 while it was $1.45 \mathrm{MPa}$.m1/2 for the neat epoxy. Different toughening mechanisms were noticed in the fracture surfaces of the composites in relation to the fibre reinforcement planar, they are shear yielding and fibre splaying with the $X$-direction and broken fibers, fibre pullout and fibre delamination with the $Y$-fibre orientation.
\end{abstract}

Keywords: Kenaf fiber; fracture toughness; alkaline treatment; fiber orientation.

\section{INTRODUCTION}

In recent years, the development of sustainable or biodegradable materials representing at using natural fibre reinforced polymer composites in commercial and medical applications has attracted a remarkable attention from both academic perspective and industrial viewpoint. This attention has emerged since these materials can be useable instead of non-renewable petroleum-based materials, particularly petroleum-based plastic due to their lighter weight, cheap and provide better stiffness to weight than glass. Additionally, by using natural fibres can preserve consumable resources such as petroleum, reducing landfill capacities, and alleviating a global warming impact due to diminishing carbon footprints that are generated by consumption of petroleum [1]. 


\section{AL-QADISIYAH JOURNAL FOR ENGINEERING SCIENCES}

Vol. 10, No. 4

ISSN: $1998-4456$

Kenaf fibres are among many different natural fibres with different chemical compositions of cellulose, lignin and hemicellulose (e.g., sisal, ramie, jute, flax, hemp, etc.), highly being used in reinforcing polymer matrix composites due to its high tensile strength and Young's modulus of $930 \mathrm{MPa}$ and $53 \mathrm{GPa}$, respectively. Kenaf as natural (plant) fibers is normally used in reinforcing polymer matrix composites. However, the main drawback of natural fibres is the complex structure of elementary fibres that contain cellulose, hemicellulose, pectin lignin and others; is its hydrophilic nature with strong hydrogen bonds and weak interfacial adhesion which complicates forming bonded interface with a relative non-polar hydrophobic matrix and resulting in poor strength properties of the produced composites [2, 3].

In order to improve the bonded interface between hydroxyl groups in natural fibres with matrix resin, thus different chemical, physical and mechanical modifications or treatments of the natural fibers have been implemented. The chemical treatments (e.g., alkaline treatment, silane treatment, isocyanate treatment, and acetylation) consider the most viable treatments, in which, reagents solution are normally used which contain functional groups that are capable of bonding with the hydroxyl group from the natural fibres. Amongst them, the alkaline treatment based on sodium hydroxide $(\mathrm{NaOH}$ ) (or mercerization) is the most widely used for natural fibers, especially for kenaf fibre when reinforcing thermoplastics and/or thermosets. Via applying the alkaline chemical treatments ensures removal of lignin, hemicelluloses, pectin, wax and oils, etc. covering the external surface of the natural fibers, breaks and disperses hydrogen bonds in the network structure and increases the number of free hydroxyl groups on the surface of the fibres and therefore fibre reactivity $[4,5]$. Additionally, the chemical treatment of the natural fibres by alkali enhances the fibre's surface roughness, which in turn causes surface fibrillization and drastically improves mechanical interlocking and fibre-matrix adhesion.

Due to the growing demand of using natural fibres-polymer composites in structural applications, there is a need to thoroughly understand the fracture toughness and behaviour of these composites especially determining maximum loads applied to the component that can be carried before creating defects, initiating microcracking and causing local stress concentrations that result in catastrophic failure. Thus, numerous studies have been identified the fracture behaviour for different natural fibres-reinforced polymer composites, and others reported the importance of chemical treatments especially alkaline treatment with sodium hydroxide $(\mathrm{NaOH})$ on mechanical and thermal properties of natural fibres/polymer composites [3, 6-8]. However, few works in the literature have conducted the influence of chemically treated natural fibres on the fracture behaviour and toughness of composites [7, 9-12].

Nosbi et al. [13] discussed the degradation of compressive properties of pultruded kenaf fibre reinforced unsaturated polyester composites. It was found that the strength and modulus of the composite are reduced and the compressive strain at failure recorded an increase due to the formation of hydrogen bonding between polymer molecules and cellulose fibers. 


\section{AL-QADISIYAH JOURNAL FOR ENGINEERING SCIENCES}

Vol. 10, No. 4

ISSN: $1998-4456$

The effect of reinforced fibre arrangements on the mechanism of toughening and fracture toughness of glass fibre-reinforced composites and natural hemp fibre-reinforced PLA was presented by [14, 15], respectively. They found that the fracture energy and toughness increases with increasing ply angle up to $40^{\circ}$ and then it decreases. Nevertheless, there is no particular study has investigated the alkaline treatment of kenaf and its arrangement (orientation) on crack path and fracture characteristics of composites. Hence, this study aims to comprehensively understand the role of treated kenaf fibres with $\mathrm{NaOH}$ in improving fracture toughness of the composites. And understanding the effect of fibre orientations (arrangements) on the fracture resistance of the composites since the properties of the fibrous composite materials are strongly affected by the fibre properties and its microstructural parameters such as fibre length and diameter, fibre distribution, fibre orientation, volume fraction of the fibers and packing arrangement of the fibers.

\section{EXPERIMENTAL}

\subsection{MATERIAL AND ALKALI TREATMENT}

Epoxy (DER331) and hardener (JOINTMINE 905-3S) with ratio of 2:1 were used as a polymer resin for kenaf fibre composites. After cleaning and extracting the kenaf fibres, portion of the prepared fibres were treated with $6 \%$ sodium hydroxide $(\mathrm{NaOH})$ solution for $24 \mathrm{~h}$ at room temperature, then washed by demineralised water and dried under sun light. The SEM micrographs for both untreated fibres and treated with $\mathrm{NaOH}$ are shown in Figure $\mathbf{1}$ a \& $\mathbf{b}$. Some specifications of the neat epoxy (NE) and untreated kenaf fibre reinforced epoxy (ut-KFRE) are listed in Table 1.

\subsection{COMPOSITES FABRICATION}

A conventional hand lay-up technique with aluminium mould of $110 \mathrm{~mm} \times 110 \mathrm{~mm} \times 16 \mathrm{~mm}$ was utilised to fabricate epoxy-kenaf composite. The mould was waxed with release agent before pouring epoxy into it to prevent cured composite from adhesion with the mould. Unidirectional kenaf fibres were then placed on top of the resin and a steel roller covered with saturated resin was used to remove air bubbles and maintain a fully impregnated between fibre and polymer resin. The procedure was repeated until the required weight fraction of kenaf fibre (30\% wt.) is consumed. The composite samples of compact tension (CT) geometry as well as a schematic graph showing different fibre orientations-reinforced composites i.e. $X$ direction and Y-direction are illustrated in Figure 2 and Figure $\mathbf{3} \mathbf{a} \boldsymbol{\&} \mathbf{b}$, respectively. 


\section{AL-QADISIYAH JOURNAL FOR ENGINEERING SCIENCES}
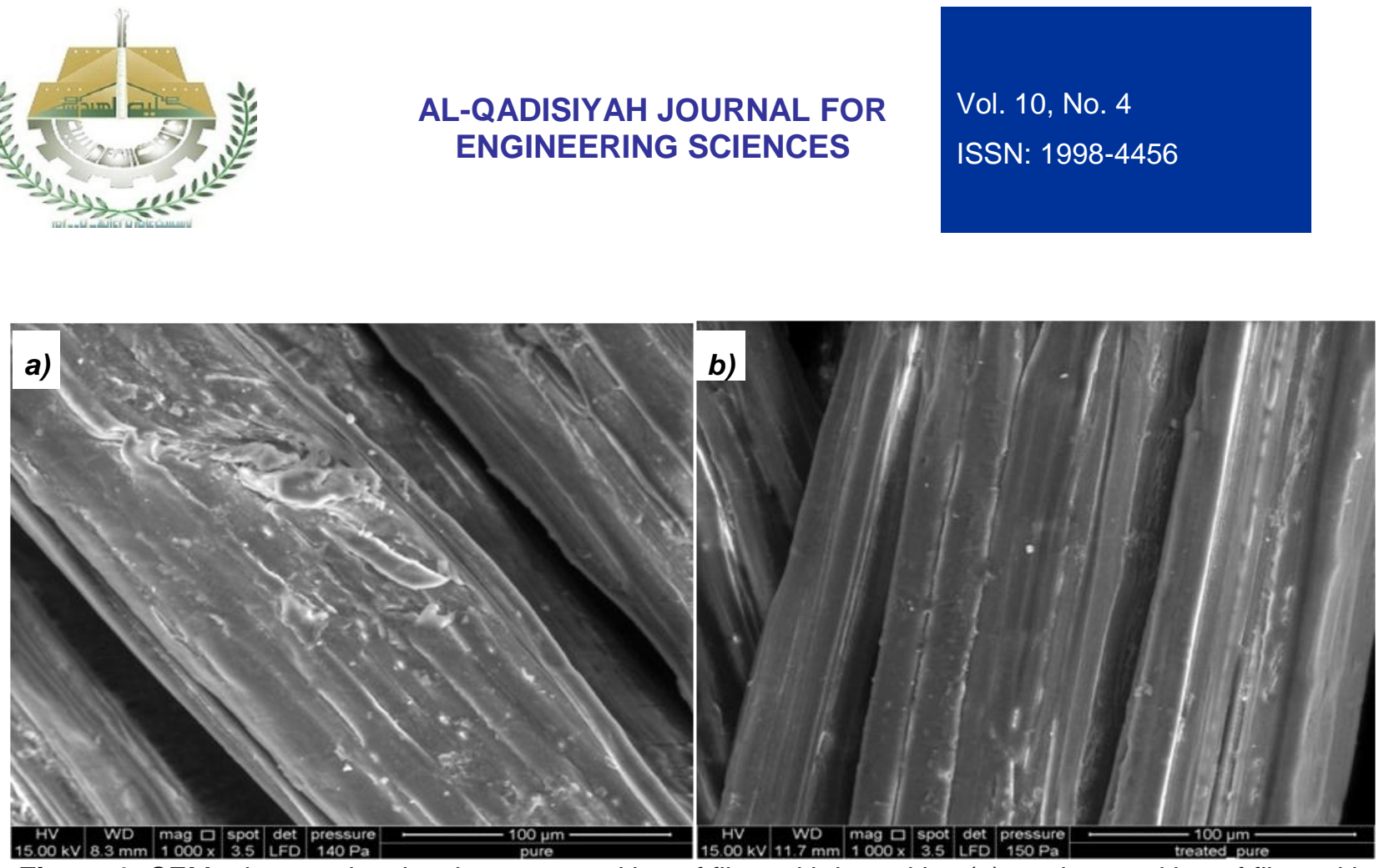

Figure 1: SEM micrographs showing untreated kenaf fibre with impurities (a), and treated kenaf fibre with exposed cellulose (b).

Table 1: Specifications of neat epoxy (NE) and untreated Kenaf fibre reinforced epoxy composite (Ut-KFRE).

\begin{tabular}{|l|c|c|}
\hline \multicolumn{1}{|c|}{ Property $^{*}$} & NE & KFRE \\
\hline Fiber volume fraction & $0 \%$ & $30 \%$ \\
\hline Density g/cm & \\
\hline Modulus of elasticity GPa & 1.1 & 0.975 \\
\hline Tensile strength $\mathrm{MPa}$ & $7.2 \pm 0.3$ & $13.5 \pm 2$ \\
\hline Elongation \% & $3.5 \pm 0.2$ & $133 \pm 2$ \\
\hline
\end{tabular}

*all given properties are experimentally measured in this study.

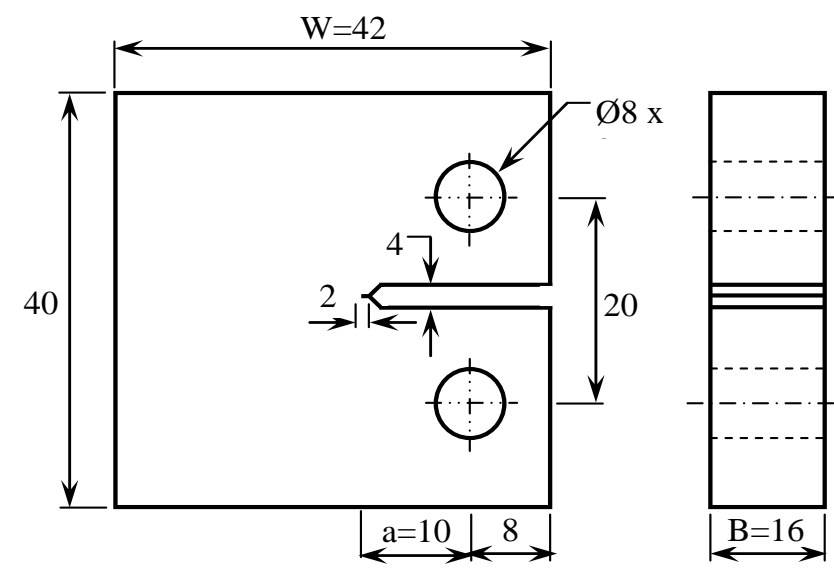

All dimensions are in $\mathrm{mm}$

Figure 2: the compact tension (CT) geometry used in this study. 

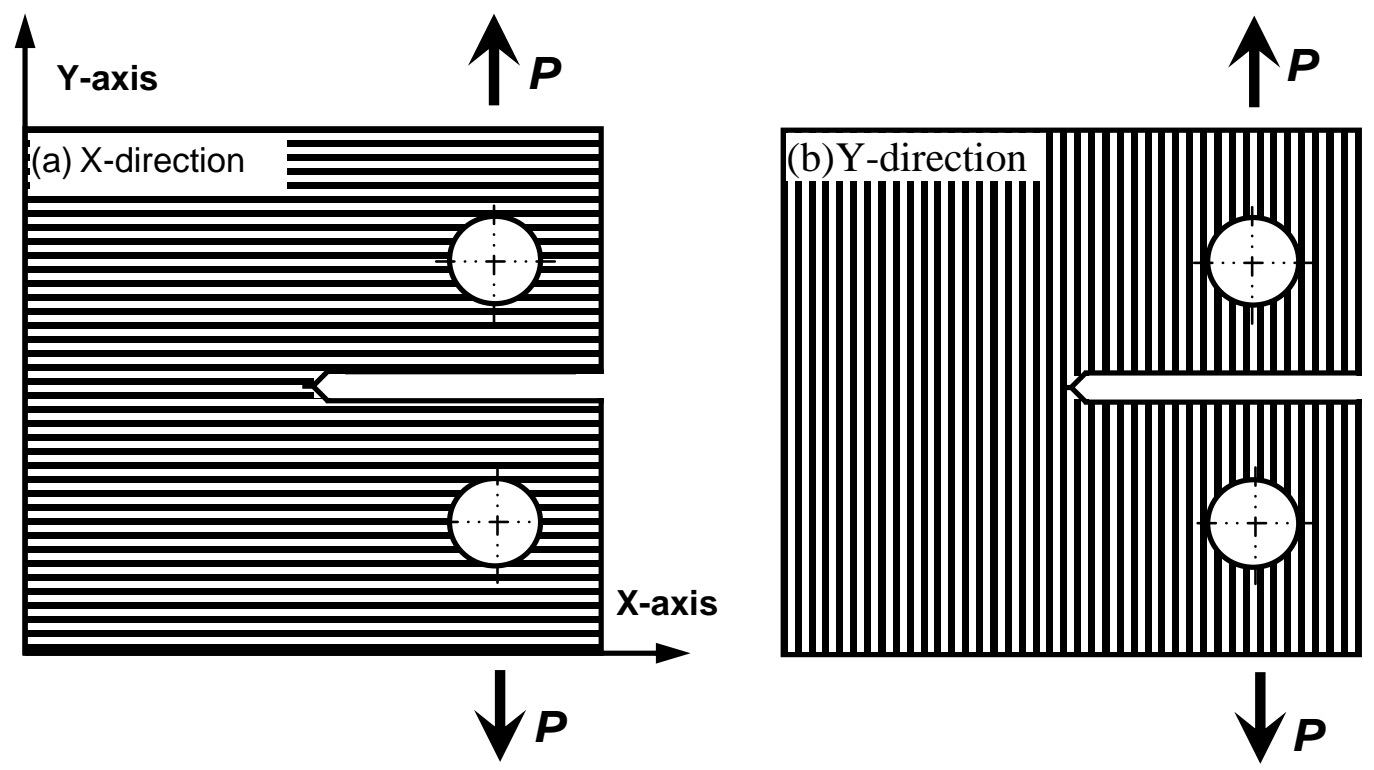

Figure 3: Schematic graph of X- direction fibre orientations in the composite (a), and Y-direction (b) according to ASTM 5045 standard.

\subsection{FRACTURE TOUGHNESS MEASUREMENT}

The neat epoxy (NE), untreated and treated kenaf fibre reinforced epoxy (ut-KFRE) and (t-KFRE) with two different orientations were cut by a diamond saw from the cured composites to dimensions of compact tension (CT) geometry according to ASTM 5045 standard [16]. The holes were opened using a steel drill, the notch and pre-crack were cut precisely with a band saw and inserting a razor blade, respectively. Fracture toughness testing was carried out using a universal tensile machine model LR $50 \mathrm{~K}$ with a crosshead speed of $1.5 \mathrm{~mm} / \mathrm{min}$. Both the load and the displacement values for five specimens from each composite direction ( $\mathrm{X}$ and $\mathrm{Y}$ ) are tested at room temperature and the averaged is recorded. A critical stress intensity factor ( $\mathrm{K}_{\mathrm{Ic}}$ ) is calculated from the following equations [16]:

$$
K_{I c}=\left[\frac{P_{Q}}{B W^{1 / 2}}\right] f\left(\frac{a}{W}\right)
$$

For a CT specimen, the shape factor, $f\left(\frac{a}{W}\right)$ is given by

$$
f\left(\frac{a}{W}\right)=\frac{2+\frac{a}{W}}{\left(1-\frac{a}{W}\right)^{3 / 2}}\left[0.866+4.64\left(\frac{a}{W}\right)-13.32\left(\frac{a}{W}\right)^{2}+14.72\left(\frac{a}{W}\right)^{3}-5.6\left(\frac{a}{W}\right)^{4}\right]
$$




\section{AL-QADISIYAH JOURNAL FOR ENGINEERING SCIENCES}

Vol. 10, No. 4

ISSN: $1998-4456$

In order to satisfy the plain-strain conditions, the following size criteria are checked:

$$
B, a,(W-a) \succ 2.5\left(K_{I c} / \sigma_{y}\right)^{2}
$$

where $P Q$ is the peak load, $B$ the specimen thickness $(16 \mathrm{~mm}),{ }^{a}$ the crack length $(10 \mathrm{~mm}), \mathrm{W}$ the specimen width $(42 \mathrm{~mm})$, and $\sigma_{y}$ the yield stress of the material.

\subsection{THE FRACTURED SURFACE STUDY}

In order to understand the mechanism of fracture and deformation behaviour, the fractured surface of the composite from Mode I fracture test was examined by using Scanning Electron Microscopy (SEM) model Quanta $400 \mathrm{~F}$. The samples were firstly coated with a thin layer of gold to improve the conductivity of the material before doing the test.

\section{RESULTS AND DISCUSSION}

\subsection{CHEMICAL TREATMENT}

The SEM images for both untreated kenaf fibres (ut-KFs) and treated kenaf fibres (t-KFs) with $6 \%$ alkali $\mathrm{NaOH}$ are shown in Figure 1 a \& $\mathbf{b}$. There is a noticeable difference between the surface morphologies for the ut-KFs and t-KFs in terms of smoothness and roughness. The characteristics of t-KFs surface considerably improved and became cleaner and smoother after the $\mathrm{NaOH}$ treatment compared to the ut-KFs. In addition, the fine fibres in the bundle are exposed after washing the outer layer of the fibres with $\mathrm{NaOH}$ while the impurities are clearly noticed in the surface morphology of ut-KFs. Hence, the $6 \%$ $\mathrm{NaOH}$ treatment is adequate to eliminate the impurities from the natural kenaf surface determined in this study. The improved surface morphology would improve the level of interfacial adhesion between the fibre and the matrix under the applied load on the fabricated fiber-reinforced polymer composites.

\subsection{FRACTURE TOUGHNESS}

The load-displacement curves for the compact tension (CT) specimens made from neat epoxy, untreated kenaf fibre reinforced epoxy (Ut-KFRE) and treated kenaf fibre reinforced epoxy (treated-KFRE) composites with two different $X$ and $Y$ fibre directions are presented in Figure 4. All CT fracture composite specimens performed better and carried higher tension loads before fracturing than neat epoxy. The composites reinforced by kenaf fibres in Y-direction conducted higher loads than these for the reinforced composites by X-direction regardless the considerations of alkali treatment method. This is an obvious indication since the neat epoxy (thermoset resin) is brittle in nature and the reinforced fibres contributed in absorb more energy and carry further load before fracturing. 
The treated-KFRE in Y-direction CT specimens had the highest tension loads before fracturing where they reached $1777 \mathrm{~N}$, giving the maximum fracture toughness $\left(\mathrm{K}_{\mathrm{Ic}}\right)$ of $2.74 \mathrm{MPa} \cdot \mathrm{m}^{1 / 2}$, which is almost double its value of $1.45 \mathrm{MPa} \cdot \mathrm{m}^{1 / 2}$ for epoxy as shown in Figure $\mathbf{5}$.

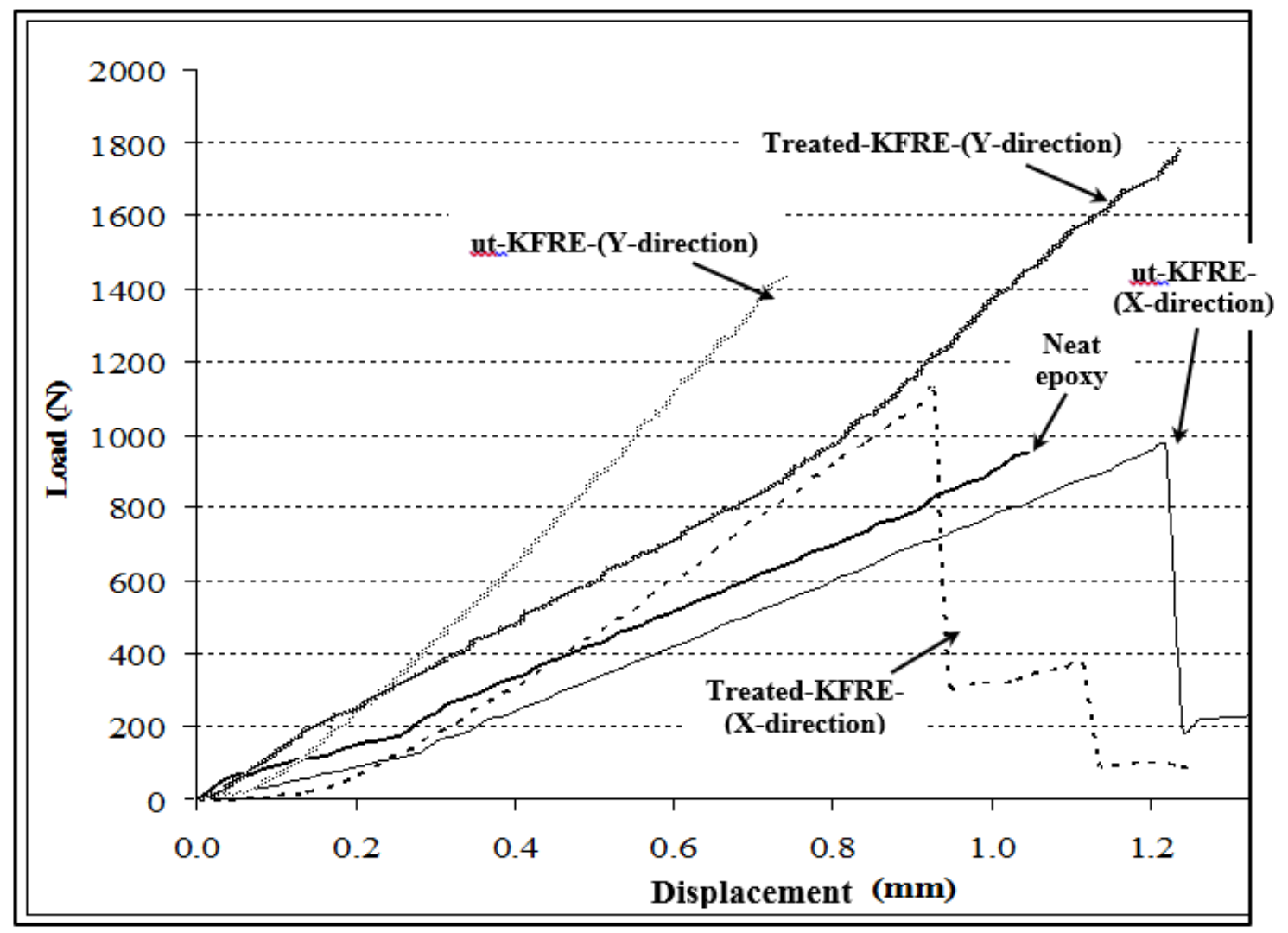

Figure 4: Load-displacement curves of the fractured CT specimens under tension.

In Figure 5, the average values of the fracture toughness $\left(\mathrm{K}_{\mathrm{Ic}}\right)$ for neat epoxy and the composites are given. The Klc values of the neat epoxy considerably increased with the existence of the reinforced KFs whether they are ut-KFs or t-KFs. The influence of the kenaf surface treatment on improving the fracture toughness is clearly observed where it contributed in an increment of about $0.5 \mathrm{MPa} \cdot \mathrm{m}^{1 / 2}$. In other words, considering of $6 \% \mathrm{NaOH}$ alkali treatment of KFs is working to improve $\mathrm{K}_{\mathrm{lc}}$ values for the ut-KFRE composites by $24 \%$ of these untreated composites without taking the orientation of fibre reinforcement in consideration. 


\section{AL-QADISIYAH JOURNAL FOR ENGINEERING SCIENCES}

Vol. 10, No. 4

ISSN: $1998-4456$

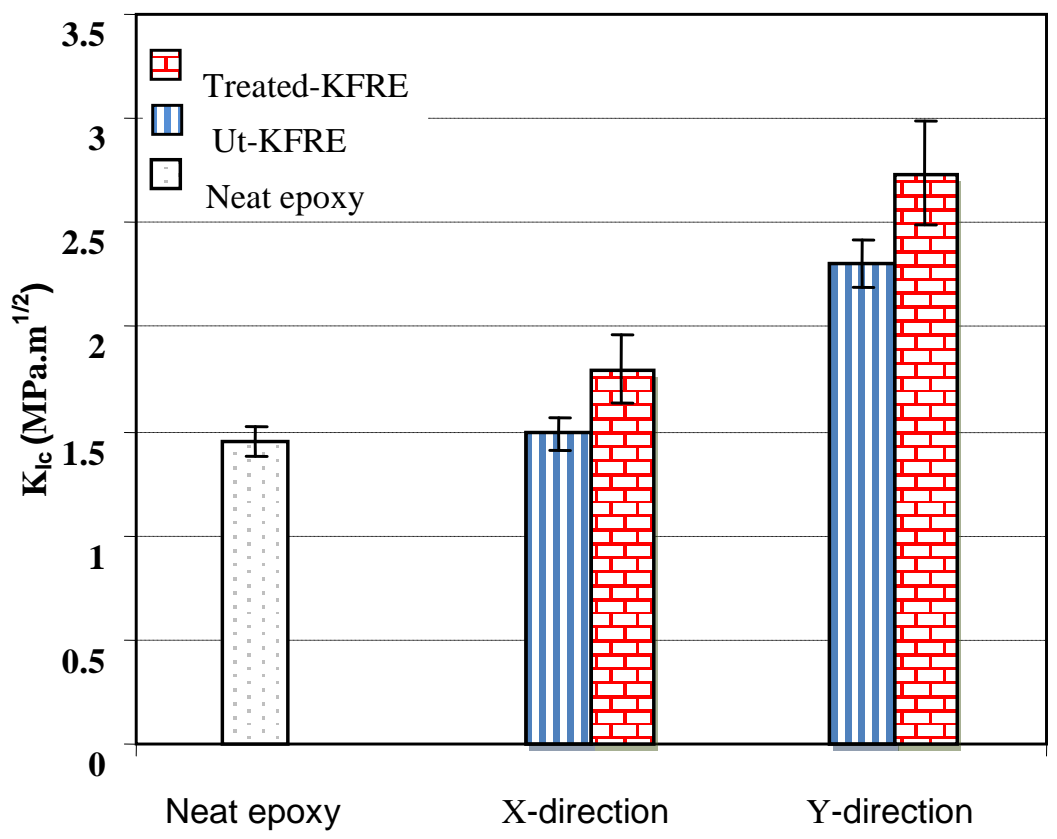

Figure 5: Fracture toughness of epoxy and composites with two KFs- reinforcement directions.

\subsection{EFFECT OF FIBRE ORIENTATIONS}

The $\mathrm{K}_{\mathrm{lc}}$ values for the treated-KFRE (Y-direction) composites are superior compared with the neat epoxy and epoxy reinforced by $\mathrm{X}$-fibre direction. This is due to the improved interfacial adhesion between the treated-KFs and epoxy which enhanced the stress-transfer from the resinous region to the fibers and consequently enhanced the $\mathrm{K}_{\mathrm{lc}}$ of the treated-KFRE composites [17]. The improved treated-KFs and epoxy adhesion may also contribute to detain the growth of the delamination, which potentially occurs under the tensile loading.

The fracture surface morphology of the neat epoxy is shown in Figure 6. It is brittle fracture showing crazing region. However, with the improved interfacial bonding between the treated-KFs and epoxy, more energy is consumed by fibre before pull-out or broken (fracturing). Using the Y-fibre to reinforce the composites in this study is further improving its toughness where the applied stress is discreet by continuous treated-KFs that can subsequently affect the toughening mechanism of the treated-KFRE composites. A similar conclusion was revealed by Fiore et al. [18], it was revealed that the use of unidirectional (UD) kenaf fibres or randomly oriented treated-KFs increased the tensile strength and tensile modulus due to the improved compatibility between fibre and epoxy. 


\section{AL-QADISIYAH JOURNAL FOR ENGINEERING SCIENCES}

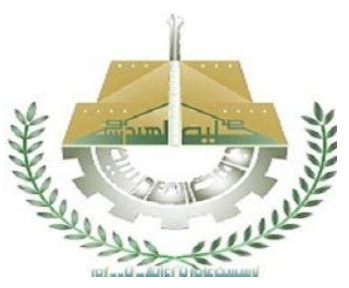

Vol. 10 , No. 4

ISSN: $1998-4456$

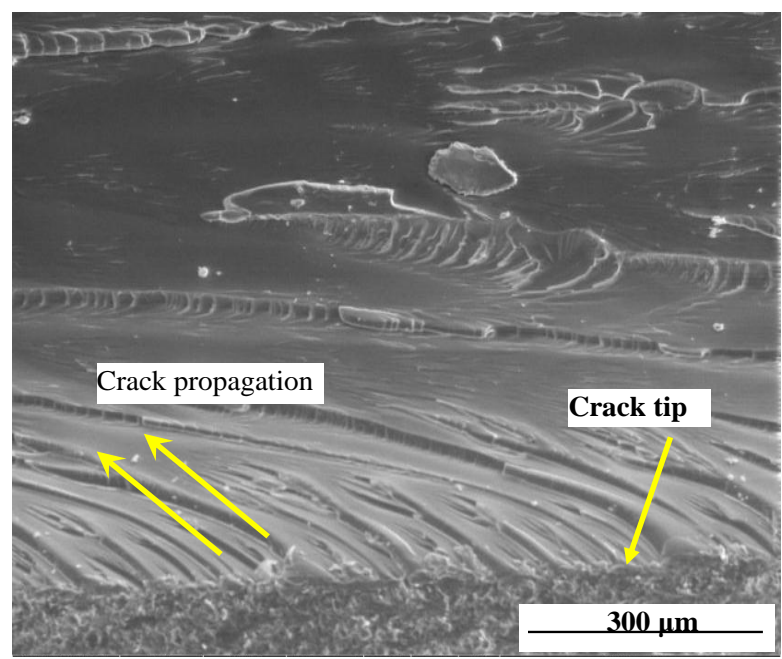

Figure 6: Fracture surface of the neat epoxy.

The fibre arrangement in anisotropic materials such as polymer-based fibre composites is playing a notable role in changing their toughening mechanisms and mechanical properties since their properties are, in general, varying through each axis and depending on the fibre direction in which they are aligned. For instance, in term of un-treated fibres aligned in X-fibre direction, it was observed that the dominant toughening method is shear yielding of the resinous region and the progressive fibre splaying (see Figure 7). The role of chemical modification on the fibre surface aligned in the same fibre direction emerged a little amount of treated KFs pull-out along with broken fibre due to the good interfaces between the fibre and matrix, as shown in Figure 8.

On the other hand, the KFRE composites reinforced by un-treated KFs oriented in $90^{\circ}$ (Y-direction) exhibited besides the fibre pull-out toughening mechanism other two mechanisms are fibre splitting and fibre delamination as shown in Fig. 9. The reason of the appearance of such mechanisms and thereof the high fracture toughness of the composites reinforced in Y-fibre direction could be attributed to the large crackbridging zones formed by intact kenaf fibres in the crack wake. The fracture surface of the treated-KFRE composites reinforced in Y-direction exhibited a broken fibre as shown in Figure 9 and Figure 10. 

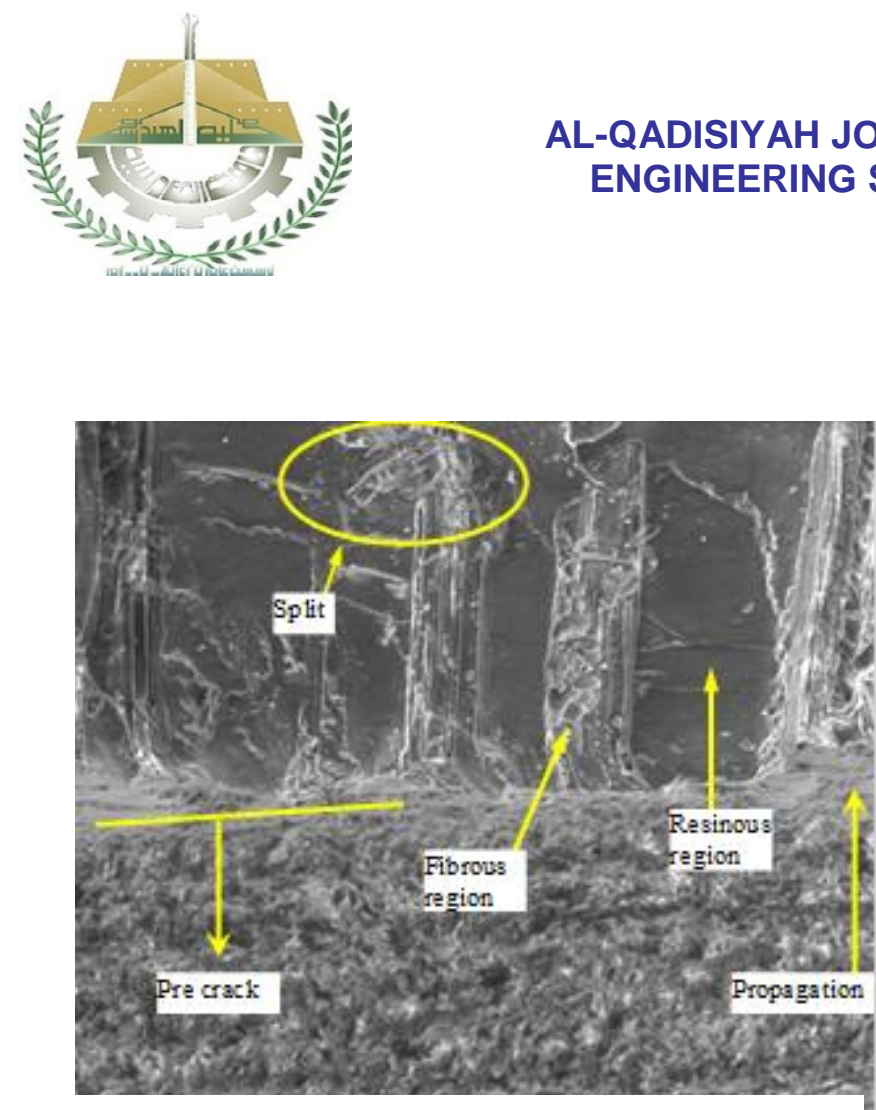

Figure 7: Fracture surface of ut-KFRE composites in X-fibre direction.

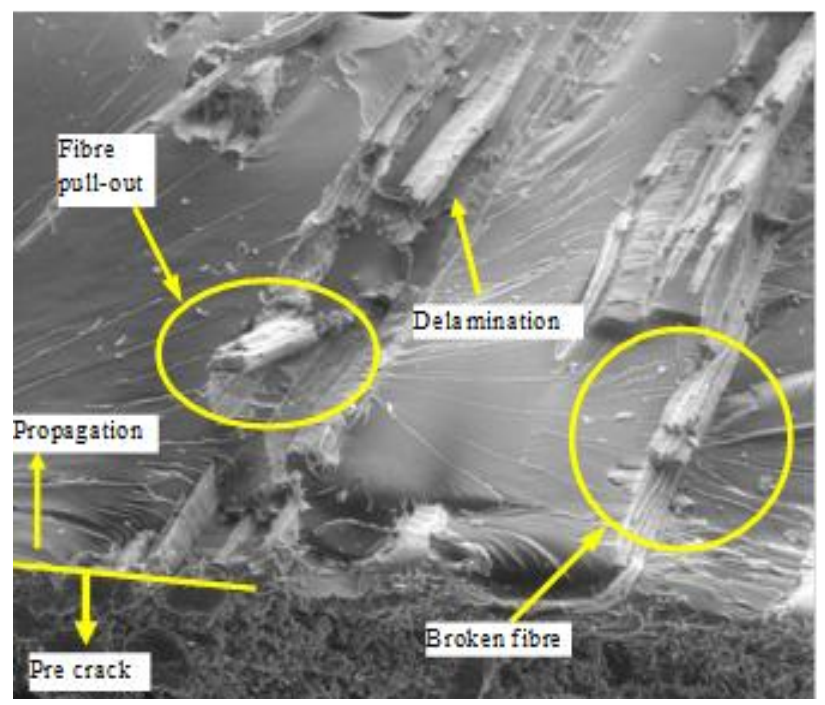

Figure 9: Fracture surface of ut-KFRE composites in Y-direction.

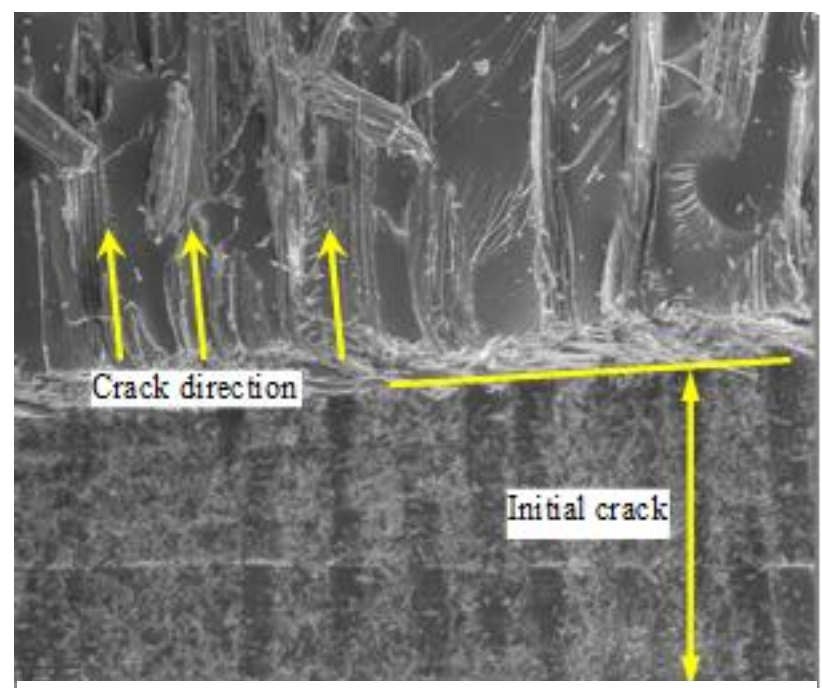

Figure 8: Fracture surface of treated-KFRE composite in X-fibre direction.

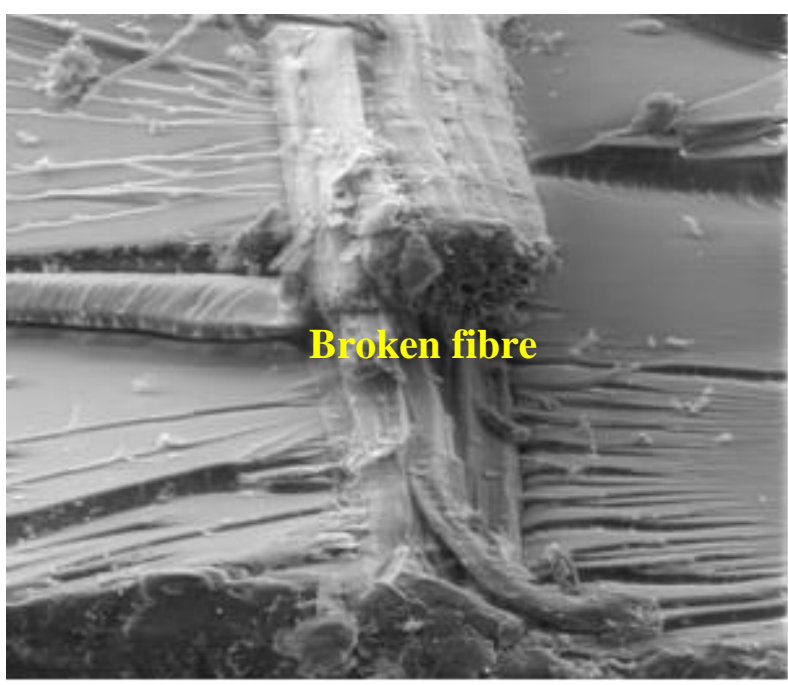

Figure 10: Fracture surface of treated-KFRE composites in Y-direction.

\section{CONCLUSIONS}

In this study, composite materials from treated kenaf fibers (KFs) with $6 \% \mathrm{NaOH}$ chemical treatment and epoxy were fabricated. Two different $X \& Y$ reinforcement fibre directions were applied. The fracture toughness $\left(\mathrm{K}_{\mathrm{lc}}\right)$ values of all composites are highly affected by the surface modification of $\mathrm{KFs}$ and dependent on the fibre orientations. The composites reinforced by treated KFs in Y-direction had the 


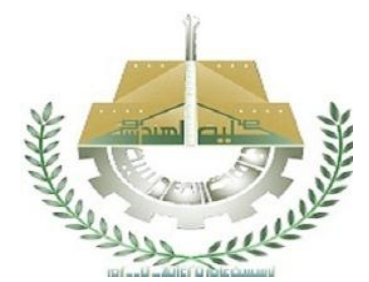

\section{AL-QADISIYAH JOURNAL FOR ENGINEERING SCIENCES}

Vol. 10, No. 4

ISSN: $1998-4456$

maximum $\mathrm{K}_{\mathrm{lc}}$ of $2.74 \mathrm{MPa} \cdot \mathrm{m}^{1 / 2}$ at $89 \%$ improvement compared to the neat epoxy. Several toughening mechanisms were observed changing with the conditions of composite materials i.e., shear yielding and little pullout for the composited reinforced by $\mathrm{X}$-direction and broken fibre and fibre delaminated as well as fibrillation for the composites reinforced by KFs in Y-direction.

\section{REFERENCES}

1. Ho M-p, Wang H, Lee J-H, Ho C-k, Lau K-t, Leng J, et al. Critical factors on manufacturing processes of natural fibre composites. Composites: Part B. 2012; 43 : 3549-3562.

2. Akil HM, Omar MF, Mazuki AAM, Safiee S, Ishak ZAM, Bakar AA. Kenaf fiber reinforced composites: $A$ review. Materials and Design 2011;32:4107-21.

3. Ibrahim NA, Yunus WMZW, Othman M, Abdan K. Effect of chemical surface treatment on the mechanical properties of reinforced plasticized poly(lactic acid) biodegradable composites. Journal of Reinforced Plastics and Composites. 2011;30(5):381-8.

4. Mussig J, Stevens C. Industrial Applications of Natural Fibres: Structure, Properties and Technical Applications. UK: John Wiley and Sons; 2010. p. 560.

5. Weyenberga IVd, Ivens J, Coster AD, Kino B, Baetens E, Verpoest I. Influence of processing and chemical treatment of flax fibres on their composites. Composites Science and Technology. 2003;63:1241-6.

6. Cordeiro N, Ornelas M, Ashori A, Sheshmani S, Norouzi H. Investigation on the surface properties of chemically modified natural fibers using inverse gas chromatography. Carbohydrate Polymers 2012;87:236775.

7. Pickering KL, Sawpan MA, Jayaraman J, Fernyhough A. Influence of loading rate, alkali fibre treatment and crystallinity on fracture toughness of random short hemp fibre reinforced polylactide bio-composites. Composites: Part A 2011;42:1148-56.

8. Roy A, Chakraborty S, Kundu SP, Basak RK, Majumder SB, Adhikari B. Improvement in mechanical properties of jute fibres through mild alkali treatment as demonstrated by utilisation of the Weibull distribution model. Bioresource Technology 2012; 107 : 222-228.

9. Liu $\mathbf{Q}$, Hughes $\mathbf{M}$. The fracture behaviour and toughness of woven flax fibre reinforced epoxy composites. Composites: Part A 2008;39:1644-52.

10. Low IM, McGrath M, Lawrence D, Schmidt P, Lane J, Latella BA, et al. Mechanical and fracture properties of cellulose-fibre-reinforced epoxy laminates. Composites: Part A 2007;38:963-74.

11. Silva RV, Spinelli D, Filho WWB, Neto SC, Chierice GO, Tarpani JR. Fracture toughness of natural fibers/castor oil polyurethane composites. Composites Science and Technology 2006;66:1328-35.

12. Wong KJ, Zahi S, Low KO, Lim CC. Fracture characterisation of short bamboo fibre reinforced polyester composites. Materials and Design 2010;31:4147-54.

13. Nosbi N, Akil HM, Ishak ZAM, Bakar AA. Degradation of compressive properties of pultruded kenaf fiber reinforced composites after immersion in various solutions. Materials and Design 2010;31:4960-4.

14. Triki E, Zouari B, Dammak F. Dependence of the interlaminar fracture toughness of E-Glass/Polyester woven fabric composites laminates on ply orientation. Engineering Fracture Mechanics. 2016;159:63-78.

15. Efendy MGA, Pickering KL. Fibre orientation of novel dynamically sheet formed discontinuous natural fibre PLA composites. Composites Part A: Applied Science and Manufacturing. 2016;90:82-9.

16. ASTM. Standard Test Method for Plain-Strain Fracture Toughness and Strain Energy Release Rate of Plastic Materials. D 5045-99. PA, United States: ASTM, Philadelphia; 2007.

17. Kafi AA, Magniez K, Fox BL. Effect of manufacturing process on the flexural, fracture toughness, and thermo-mechanical properties of bio-composites. Composites: Part A 2011;42:993-9.

18. Fiore V, Bella GD, Valenza A. The effect of alkaline treatment on mechanical properties of kenaf fibers and their epoxy composites. Composites: Part B. 2015;68:14-21. 